12 Rushton J, Bruckman D, Kelleher K. Primary care referral of children with psychosocial problems. Arch Pediatr Adolesc Med 2002; 156: 592-8.

13 Bergen $\mathrm{H}$, Hawton K. Variation in deliberate self-harm around Christmas and New Year. Soc Sci Med 2007; 65: 855-67.

14 Bergen $\mathrm{H}$, Hawton $\mathrm{K}$. Variations in time of hospital presentation for deliberate self-harm and their implications for clinical services. J Affect Disord 2007; 98: 227-37.

15 Blenkiron P. The timing of deliberate self harm behaviour. Ir J Psychol Med 2003; 20: 126-31.

16 Jessen G, Steffensen P, Jensen BF. Seasons and meteorological factors in suicidal behaviour. Arch Suicide Res 1998; 4: 263-80.

17 Office for National Statistics. Census 2001: the most comprehensive survey of the UK population. ONS, 2001 (http:/www.statistics.gov.uk/ census2001/census2001.asp).
18 Hakko H, Rasanen P, Tiihonen J, Nieminen P. Use of statistical techniques in studies of suicide seasonality, 1970 to 1997. Suicide Life Threat Behav 2002; 32: 191-208.

19 Worrall A, O'Herlihy A, Banerjee S, Jaffa T, Lelliott P, Hill P, et al Inappropriate admission of young people with mental disorder to adult psychiatric wards and paediatric wards: cross sectional study of six months' activity. BMJ 2004; 328: 867-8.

20 Parker $\mathrm{KCH}$, Roberts N, Williams C, Benjamin M, Cripps L, Woogh C. Urgent adolescent psychiatric consultation: from accident and emergency department to inpatient adolescent psychiatry. J Adolesc 2003; 26: 283-93.

21 Eastwood MR, Stiasny S. Psychiatric disorder, hospital admission, and season. Arch Gen Psychiatry 1978; 35: 769-71.

22 Hawton K, Hall S, Simkin S, Bale L, Bond A, Codd S, et al. Deliberate selfharm in adolescents: a study of characteristics and trends in Oxford, 1990-2000. J Child Psychol Psychiatry 2003; 44: 1191-8.

\title{
Assessing the security needs of patients in medium secure psychiatric care in Northern Ireland
}

\author{
Rowan James McClean ${ }^{1}$
}

The Psychiatrist (2010), 34, 432-436, doi: 10.1192/pb.bp.109.027672

${ }^{1}$ Knockbracken Healthcare Park, Belfast

Correspondence to Rowan James McClean

(rowanmcclean@doctors.org.uk)
Aims and method To determine the security needs of patients in medium secure services in Northern Ireland and to identify those requiring long-term secure care. Patients were rated on the Security Needs Assessment Profile.

Results Fifteen patients (45\%) could be managed in conditions of low security. Twelve patients (36\%) require over 5 years' further treatment in secure care. Particular security needs include relational nursing skills, restricted access to alcohol and drugs, and robust physical security.

Clinical implications This study should be replicated across the UK to determine whether forensic services are responding to patients' needs. Pathways out of medium security need to be better developed, with regional expansion of low secure services.

Declaration of interest None.
A lack of clear definitions of levels of security within psychiatric services has led to significant variation in purpose and characteristics of low and medium secure units throughout the UK. This problem is compounded by a paucity of reliable, valid tools suitable to assess an individual's security needs and match these to an appropriate unit. This study aims to assess the needs of patients within a new and developing medium secure unit in order to ensure that patients are appropriately placed and to guide future development of forensic services.

Medium secure units emerged throughout the UK in the 1980s following the Glancy and Butler reports. ${ }^{1-3}$ These units generally manage patients discharged from special hospitals (hospitals which treat psychiatric patients in high security because of their potential risk to others) or those transferred from prisons and courts. There is a wide variation between medium secure units across the UK, for example in the level of physical security provided. There is a similar variation in purpose and characteristics of the next step down in security, the low secure unit, which generally provides longer-term rehabilitation for chronically disturbed patients. As a result of this variation in standards and the large numbers of delayed transfers, published needs assessments have illustrated a considerable degree of inappropriate placement within the overall system. ${ }^{4}$ For example, Shaw et $a l^{5}$ found that $79 \%$ of patients in secure care in a sampled UK health region were placed at a level of security that was inappropriate to their needs.

Other problems have been noted with the current provision of low and medium secure units across the UK. Turner \& Salter ${ }^{6}$ highlight that beds in medium secure units are logjammed and that disputes over responsibilities and the appropriate use of resources have led to strained relations between forensic and general adult psychiatrists. 
They propose large-scale expansion of low secure facilities in order to address these problems. Pereira et $a l^{7}$ suggest that a lack of low secure provision may contribute to the significant problem of delayed discharges in psychiatric intensive care units. There is also a concern that some patients may be detained in excessive security because of a lack of availability of the right treatment in lower secure provision, such as appropriate psychological treatment.

Northern Ireland has a developing regional network of forensic mental health services. Its first medium secure unit, Shannon Clinic, opened in 2005, and caters for up to 34 patients across three wards. Ward 1 provides assessment and intensive care, Ward 2 offers intermediate care and has a dedicated female area, and Ward 3 provides ongoing rehabilitation. The clinic aims to treat individuals for up to 2 years.

The aims of the study were to determine the security needs of all patients resident in medium security in Northern Ireland and the level of security these patients need. It aims to identify any aspects of security that are particularly important in this group of patients and to assess how many of these individuals require longer-term secure care. Using the findings in respect of security need, the study considers the implications for the future development of forensic services at all levels of security throughout the UK.

\section{Method}

Several complex areas have to be addressed in defining a patient's individual needs for security. In order to assess the security needs of patients in Shannon Clinic, the Security Needs Assessment Profile $(\mathrm{SNAP})^{8}$ was used. This tool provides a systematic framework to examine individual patient security need across open, low, medium and high secure forensic mental health services.

The SNAP examines the three traditional dimensions of security: physical, procedural and relational. Each dimension is subdivided into a number of items, with 22 items overall. The four physical security items are: perimeter, internal security, entry and facilities. The 14 procedural security items are: nursing intensity, environment, searching, access to potential weapons and fire-setting materials, internal movement, leave, external communications, visitors, visiting children, media exposure, and access to illicit substances, alcohol, pornography and information technology. The four relational skills items are: management of violence and aggression, relational nursing skills, response to nursing interventions and treatment programme, and security intelligence and police liaison. Each item is described on a four-point ordinal scale, with 0 the absence of security need and 3 representing the highest level. Each item is rated in relation to the current needs and risk profile of the patient and the security necessary to manage the risk that the patient poses to self or others.

The SNAP has been validated by its authors, ${ }^{8}$ providing mean overall scores for open, low, medium and high secure best placement. The mean score for an open ward is 15.11, for low security 26.19, for medium security 32.39 and for high security 49.75 . These mean scores can be used as rough indicators of the scores required for each level of security, as an aid to clinical judgement.

To assess the security needs of patients in Shannon Clinic, individual meetings with each patient's responsible medical officer (RMO) took place over the course of 1 week. Each patient was rated jointly on the SNAP by the researcher and the RMO; one RMO's patients were also jointly rated with other members of the multidisciplinary team. Basic patient characteristics were obtained, including age, gender, date of admission and diagnosis. Each RMO was asked to give their clinical opinion as to the appropriate level of security in which the patient could be managed. They were also asked to estimate the likely further length of stay at the appropriate level of secure psychiatric care. This opinion was based mainly on the patient's stability, insight and risk assessment. Data were analysed using Microsoft Excel on Windows (Microsoft Office XP).

\section{Results}

\section{Patient characteristics}

In total, 33 patients were assessed: 30 males and 3 females. Patients' ages ranged from 19 to 60 years, with an average age of 36.8 years. There was no significant relationship between patient age and overall total SNAP score.

The majority of patients had a primary diagnosis of paranoid schizophrenia, with other primary diagnoses including drug-related psychosis, schizoaffective disorder and delusional disorder. Secondary diagnoses included dissocial and emotionally unstable personality disorder, alcohol and cannabis dependence, and mild intellectual disability.

\section{Clinical opinion of best placement and duration of treatment}

In addition to rating each patient on the SNAP, the RMOs gave their clinical opinion as to what level of security the patient required to be safely treated and have their level of risk managed. Sixteen patients $(48 \%)$ were considered to require medium security. It was indicated that 2 patients (6\%) could be managed in an open ward and 15 patients $(45 \%)$ in a low secure unit. No patients were thought to require high security.

The RMOs were also asked to estimate the likely duration of treatment each patient required at the appropriate level of security. Twelve patients (36\%) were thought to require up to 2 years' further treatment. Nine patients (27\%) needed between 2 and 5 years of treatment, four of whom needed to remain in medium security. Twelve patients (36\%) required more than 5 years of further treatment, with three requiring long-term medium security and nine requiring long-term low security.

Fourteen patients (42\%) had been in Shannon Clinic for over 2 years at the point of data collection. Nine of these patients were considered to require more than 5 years' further secure care. 


\section{SNAP scores}

The overall total SNAP scores ranged from 14 to 47 (mean 30.3) (Fig. 1). Four patients (12\%) had SNAP total scores closest to the mean score for an open ward. Ten patients $(30 \%)$ had a SNAP total score closest to the mean score for a low secure ward. Fifteen patients $(45 \%)$ scored closest to the mean score for medium security and four (12\%) scored closest to the mean score for high security. The SNAP has not been validated as an actuarial score that determines the level of security required, but these scores could be used as an aid to clinical decision-making. It is notable that the number of patients allocated to each level of security using these mean scores is similar to the numbers obtained using the RMO clinical opinion.

The mean overall total scores were calculated for each ward, along with standard deviations and 95\% confidence intervals (Table 1). There was a significant range of scores in all three wards, with considerable overlap between the wards.

A one-way ANOVA was conducted to compare the overall total SNAP scores between the three wards. There was a significant difference between overall SNAP scores at the $P<0.05$ level $(F(2,30)=5.22, P=0.01)$. There is a statistically significant decline in security need of patients from Ward 1 to Ward 3. Ward 3 contains patients with significantly lower security needs, who could potentially be managed in a low secure environment.

Mean scores were calculated for each item of the SNAP, displayed in descending order in Table 2. This highlights that particular areas of security need for these patients included high relational nursing skills, engagement with treatment, restricted access to alcohol and illicit drugs, restrictions on periods of leave and robust physical security.

\begin{tabular}{lcc} 
Table 1 & $\begin{array}{l}\text { Mean SNAP overall total scores across the three } \\
\text { wards }\end{array}$ \\
\hline Ward 1 & $34.2(8.6)$ & $95 \% \mathrm{Cl}$ \\
\hline Ward 2 & $31.4(8.1)$ & $29.5-38.9$ \\
\hline Ward 3 & $24.2(4.4)$ & $21.5-26.9$ \\
\hline
\end{tabular}

SNAP, Security Needs Assessment Profile.

Length of admission at the point of data collection ranged from 5 to 199 weeks. There was no significant relationship between duration of admission and SNAP overall total score.

\section{Discussion}

This study found that 15 of the 33 patients in medium security in Northern Ireland $(45 \%)$ could potentially be managed in a low secure setting, with a further 2 patients (6\%) who could potentially be managed in an open ward. There is a significant difference in security needs between the three wards, with patients in Ward 3 being primarily 'low secure'. Approximately a third of patients require more than 5 years of further treatment in a secure psychiatric facility, $9 \%$ require long-term treatment in medium security and $27 \%$ require long-term treatment in low security.

These results are comparable with those of Reed, ${ }^{9}$ who conducted a survey of all National Health Service and independent sector medium secure units in England and Wales. It was concluded that $15 \%$ of these patients required long-term medium security based on the views of their

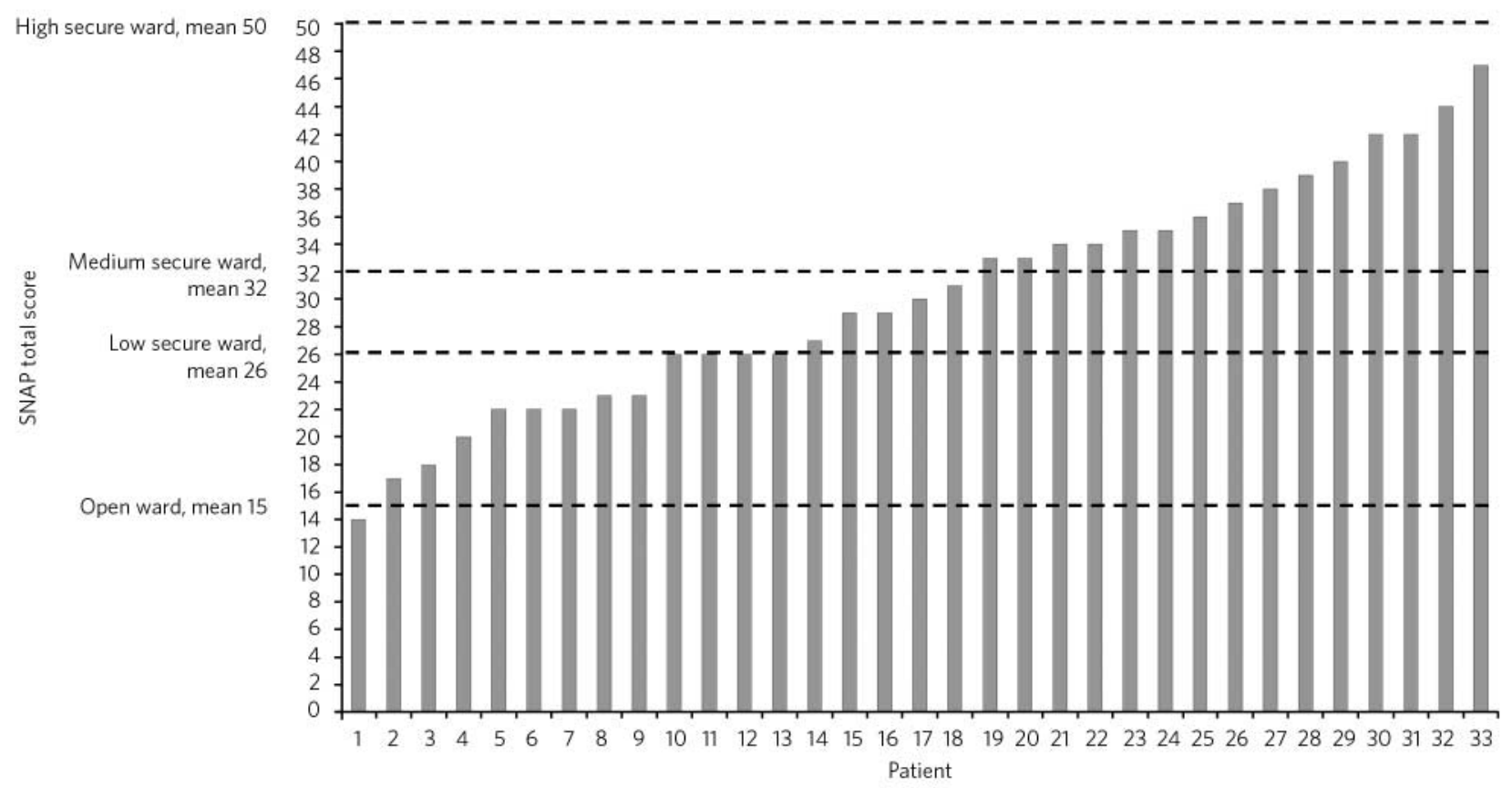

Fig 1 SNAP overall total scores for each patient, in ascending order, with means for each security level. ${ }^{a}$ 


\begin{tabular}{|c|c|}
\hline Item $^{a}$ & $\begin{array}{l}\text { Average } \\
\text { score }\end{array}$ \\
\hline 16 Access to alcohol & 2.4 \\
\hline 20 Relational nursing skills & 2.0 \\
\hline $\begin{array}{l}21 \text { Response to nursing interventions and treatment } \\
\text { programme }\end{array}$ & 2.0 \\
\hline 10 Leave & 1.6 \\
\hline 15 Access to illicit substances & 1.6 \\
\hline 19 Management of violence and aggression & 1.6 \\
\hline 3 Entry & 1.5 \\
\hline 4 Facilities & 1.5 \\
\hline 12 Visitors & 1.5 \\
\hline 13 Visiting children & 1.5 \\
\hline 1 Perimeter & 1.4 \\
\hline 6 Environment & 1.4 \\
\hline 9 Internal movement & 1.4 \\
\hline 2 Internal security & 1.3 \\
\hline $\begin{array}{l}8 \text { Access to potential weapons and fire-setting } \\
\text { materials }\end{array}$ & 1.3 \\
\hline 5 Nursing intensity & 1.1 \\
\hline 17 Access to pornographic materials & 1.1 \\
\hline 7 Searching & 1.0 \\
\hline 18 Access to information technology equipment & 0.9 \\
\hline 11 External communications & 0.8 \\
\hline 14 Media exposure & 0.7 \\
\hline 22 Security intelligence/police liaison requirements & 0.6 \\
\hline
\end{tabular}

SNAP, Security Needs Assessment Profile.

a. Item numbering reflects that in SNAP.

consultant psychiatrist. A further $21 \%$ were thought to require long-term low secure care.

Forensic services across the UK generally provide a medium secure service, with less emphasis on the other levels of security. This study highlights that the needs of the forensic in-patient population of Northern Ireland could be met across a range of security levels. The SNAP identified that particularly important aspects of security in this cohort of patients include high relational nursing skills, engagement with treatment and management of violence and aggression. Those individuals whose security needs revolve around relational security more so than physical security could potentially be managed in a low secure setting with a carefully tailored care plan, rather than being unnecessarily restricted in medium security. The SNAP may have a role in identifying these individuals as an aid to structured professional judgement.

There are several routes out of medium-term medium secure units, but often these alternatives are underdeveloped and underfunded. One option is long-term medium security, often provided by the private sector, but not currently available in Northern Ireland. An alternative is long-term low security. There is considerable variation in low secure provision throughout Northern Ireland, as there is elsewhere in the UK, both in terms of the number of places available and the quality of rehabilitation and therapeutic interventions. This may highlight the need for expansion of low secure services on a regional basis, as has been suggested in England, in order to accommodate patients 'stepping down' from medium security. In order to get a true picture of the scale of low secure provision that is required, it would be useful to examine delayed discharges in psychiatric intensive care units and to identify individuals with frequent admissions to general adult psychiatric wards whose needs would be best met in a low secure environment.

An alternative route out of medium security is to supported community accommodation. Again, there are limited resources and options in this area, particularly for patients in forensic services. Community placements can be strengthened by the involvement of specialist community forensic mental health teams. These teams can provide assertive treatment in the community and could also potentially provide in-reach services to low secure units and open wards in order to accommodate these patients at lower levels of security. This may require greater co-working between forensic services and general adult psychiatry.

Throughout the UK there is a need to establish better pathways out of medium security. This would improve patient flow throughout the system of secure care and could allow for greater diversion of individuals from prison and courts into mental healthcare. Patients would be cared for in the least restrictive environment necessary and limited resources could be employed most effectively and efficiently.

This study suggests that in Northern Ireland a lack of low secure provision and supported community placements is contributing to some patients being treated in a higher level of security than they necessarily require. This problem may be compounded by forensic services in general seeing their role as providing a medium secure service. This study should be replicated on a UK-wide basis in all medium secure beds to determine whether forensic services are dictating the security level of provision or are responding to the needs of their population.

\section{Limitations}

The sample size was quite small, although it did encompass all patients resident in medium security in Northern Ireland at the point of data collection. Although the same researcher scored all 33 patients, four different RMOs were involved, which could have led to variation in the results. The SNAP has not been validated as an actuarial tool and therefore overall total scores should only be used as an aid to clinical judgement. An individual's score may only be valid for one particular moment in time, and one incident or change in their presentation may considerably alter what they would subsequently score on the SNAP. It has not been demonstrated that each item on the SNAP is of equal importance, and if this is not the case, then the score on each would require weighting to produce an accurate overall score. Although an individual patient may only score highly on a few discrete items, they may still require a high level of security if those few items make it unsafe for that individual to be managed elsewhere. 


\section{Acknowledgements}

I would like to thank Mr Michael Collins and Dr Steffan Davies for their permission to use the Security Needs Assessment Profile for this research, Dr Christine Kennedy for her advice and support at all stages, Mr Hugo Kelly, and the responsible medical officers who took part.

\section{About the author}

Rowan James McClean is Specialty Registrar ST6 at Knockbracken Healthcare Park in Belfast, UK.

\section{References}

1 Department of Health and Social Security. Revised Report of the Working Party on Security in NHS Psychiatric Hospitals (Glancy Report). HMSO, 1974

2 Home Office, Department of Health and Social Security. Report of the Committee on Mentally Abnormal Offenders, CMND 6244 (Butler Report). HMSO, 1975
3 Beer MD. Psychiatric intensive care and low secure units: where are we now? Psychiatr Bull 2008; 32: 441-3.

4 Kennedy HG. Therapeutic uses of security: mapping forensic menta health services by stratifying risk. Adv Psychiatr Treat 2002; 8: 433-43.

5 Shaw J, Davies J, Morey $\mathrm{H}$. An assessment of the security, dependency $\&$ treatment needs of all patients in secure services in a UK health region. J Forens Psychiatry Psychol 2001; 3: 610-37.

6 Turner T, Salter M. Forensic psychiatry and general psychiatry: reexamining the relationship. Psychiatr Bull 2008; 32: 2-6.

7 Pereira SM, Sarsam M, Bhui K, Paton C. The London Survey of Psychiatric Intensive Care Units: service provision and operational characteristics of National Health Service units. J Psychiatr Intensive Care 2005; 1 : 7-15

8 Collins M, Davies S. The Security Needs Assessment Profile: a multidimensional approach to measuring security needs. Int J Forens Ment Health 2005; 4: 39-52.

9 Reed J. The need for longer term psychiatric care in medium or low security. Crim Behav Ment Health 1997; 7: 201-12.

\title{
Irish Mental Health Act 2001: impact on involuntary admissions in a community mental health service in Dublin
}

\author{
Izu Nwachukwu, ${ }^{1}$ Niall Crumlish, ${ }^{2,3}$ Elizabeth A. Heron, ${ }^{3}$ Michael Gill ${ }^{3}$
}

The Psychiatrist (2010), 34, 436-440, doi: 10.1192/pb.bp.109.028043

${ }^{1}$ St Vincent's University Hospital, Dublin; ${ }^{2}$ St Davnet's Hospital, Monaghan; ${ }^{3}$ St James's Hospital, Dublin, Ireland

Correspondence to Izu Nwachukwu (izunwachukwu@hotmail.com)

\begin{abstract}
Aims and method On 1 November 2006, Ireland's Mental Health Act 2001 was implemented, replacing the country's Mental Treatment Act 1945. We aimed to assess the impact of this change in legislation on the number and duration of involuntary admissions. We undertook a retrospective review of all admissions to a psychiatric admissions unit from January to October 2006 (pre-implementation) and January to October 2007 (post-implementation).
\end{abstract}

Results There were 46 involuntary admissions in the 10-month period under study in 2006, or 33.8 per 100000 population. There were 53 in 2007, or 39.3 per 100000 population. This increase was not significant $(z=-0.7, P=0.46)$, however involuntary admissions formed a larger proportion of all admissions under the Mental Health Act 2001 than under the Mental Treatment Act $1945\left(\chi^{2}=4.2, P=0.04\right)$. There was no difference in the duration of involuntary admissions but under the 2001 Act, involuntary patients had longer periods of voluntary status as part of their admissions than under the 1945 Act.

Clinical implications The introduction of more rigorous procedures for involuntary admission did not significantly change the rate or duration of involuntary admissions in our centre. The finding that involuntary admissions included longer periods of voluntary status suggests that more care is being taken to revoke involuntary admission orders under the Mental Health Act 2001 than under the Mental Treatment Act 1945.

Declaration of interest None.
On 1 November 2006, the Mental Health Act 2001 was implemented in Ireland, replacing the Mental Treatment Act of 1945. Among other provisions, the 2001 Act introduced stricter procedures governing involuntary admissions to designated 'approved centres' for treatment of mental disorders, driven by a recognition that the 1945 Act breached the civil rights of involuntary patients. ${ }^{1,2}$ Most notably, the 1945 Act made no provision for automatic 